\title{
Connective Witnessing
}

\section{Reconfiguring the Relationship between the Individual and the Collective}

Mortensen, Mette

Published in:

Information, Communication \& Society

DOI:

10.1080/1369118X.2015.1061574

Publication date:

2015

Document version

Peer reviewed version

Citation for published version (APA):

Mortensen, M. (2015). Connective Witnessing: Reconfiguring the Relationship between the Individual and the Collective. Information, Communication \& Society, 18(11), 1393-1406.

https://doi.org/10.1080/1369118X.2015.1061574 


\section{Connective witnessing: Reconfiguring the relationship between the individual and the collective}

\section{Mette Mortensen}

To cite this article: Mette Mortensen (2015) Connective witnessing: Reconfiguring the relationship between the individual and the collective, Information, Communication \& Society, 18:11, 1393-1406. Please use the page number of the final article printed in Information, Communication \& Society when referencing this article

To link to this article: http://dx.doi.org/10.1080/1369118X.2015.1061574 
Abstract: This article proposes the term 'connective witnessing' to designate the prevalent form of witnessing today that combines personalized political participation and connective action in the recording and sharing of visual documentation. Connective witnessing manifests itself in various situations, prompting the production and distribution of eyewitness images on a large scale, for example, citizens contributing to crisis communication and news coverage of man-made or natural catastrophe. Civic action has been chosen as the empirical example in this article because it constitutes a fairly new-coming and rapidly developing domain of connective witnessing. Connective witnessing merges two distinct scholarly traditions, concerned with, respectively, witnessing in and through media and the deployment of digital communication technologies by protest movements. Drawing on these two traditions, the article develops a theoretical framework for understanding connective witnessing, which is exemplified through analysis of images produced and disseminated by protesters on Ireport, CNN.com's platform for citizen reporting.

Keywords: media studies; social movements; social networking; communication studies; connective witnessing; eyewitness images

In his seminal essay 'Witnessing' from 2001, John Durham Peters emphasizes that witnesses do not become aware of themselves until after the closure of an event (p. 722), when they are called upon to perform the ritualized role of bearing testimony within the confines of a media insti- tution vouching for their legitimacy and relevance. A mere decade and a half later, this no longer holds true. Individuals on site with no or informal institutional affiliations assume this role on their own initiative, occasioning both qualitative and quantitative changes to practices of witnessing. The witness used to enjoy an exclusive position, typically inhabited by selected victims or bystanders to catastrophic events, who were thought to lend voice and face to collec- tive experiences in invited media appearances. Witnessing today takes place on a massive scale, across media platforms and contexts. In step with the profusion of digital technologies in every- day life, the number of witnesses and events witnessed has grown dramatically. Testimonies spread and shared in the 'ecosystem of connective media' (Dijck, 2013, p. 4) create both per- sonalized and collaborative possibilities for generating patterns of meaning, even if much footage is also consigned to oblivion due to the sheer amount of witness accounts and the density and diffusion of connective culture. 'Immediacy of access, versus volume, seems to be a paradoxical product of the digital', as Hoskins remarks on the related phenomenon 'con- nective memory' (2011, p. 269).

Research in the field has predominantly focused on the use of selected eyewitness images in the news coverage (e.g. Allan, 2013; Andén-Papadopoulos \& Pantti, 2011; Mortensen, 2015). Less attention has been devoted to the large accumulation of testimonies on connective platforms, which, from the perspective of this article, is of particular interest, because it reconfigures the con- ventional relationship between the individual and the collective essential to witness testimonies. Contemporary witness accounts still hold as their pivotal point the relationship between the individ- ual and the collective, but this has been transformed considerably by digital technologies enabling witnesses to produce and distribute testimonies themselves. Witnessing has become a participatory and reflective act. This constitutes a change compared to how bearing testimony was earlier divided into two distinct phases of 'private experience' and 'public statement' according to John Durham Peters, who also describes them as 'the passive one of seeing and the active one of saying' (2001, p. 709). Many contemporary witnesses eliminate the distance in time and space between 'seeing' and 'saying' by recording events on location as they play out (Mortensen, 2015).

In all, the current transformation of witnessing concerns both the position of the individual witness and the understanding of the collective addressed and sometimes also represented by the testimony. This article proposes the 
term 'connective witnessing' to designate the contempor- ary mode of witnessing distinguished by online sharing of footage from situations of crisis or con- flict, which has been recorded by individuals present on site mostly as participants (but sometimes also as bystanders). The aim of this article is twofold: (1) to introduce the concept 'connective witnessing' in continuation of the existing research on witnessing and (2) to examine how this proliferating form of witnessing reconfigures the relationship between the individual and the col- lective central to witnessing.

This article is indebted to research on the witness and witnessing emerging from the 1990s (e.g. Felman \& Laub, 1992) and resumed again in recent years to underpin theoretically the modes of citizen witnessing facilitated by digital technologies (e.g. Allan, 2013, 2014a, 2014b; Andén-Papadopoulos, 2014; Chouliaraki, 2010; Mortensen, 2011a, 2011b, 2014, 2015; Pantti, 2013; Reading, 2009). Originating mostly from the humanities, scholarship on witnessing is mainly preoccupied with the way and extent to which testimonies from singular individuals may be said to deal with collective experiences. However, in order to understand the changing relationship between the individual and the collective, this article also draws on research, typically deriving from political science and sociology, on the connectivity supporting or even substituting collectivity in today's protest movements. 'Public experiences of the self' (McDonald, 2002) and 'connective action' (Bennett \& Segerberg, 2012, 2013) have replaced the more firmly defined col- lective identities that used to distinguish the organization and execution of civic action. The research traditions on witnessing and civic action emerge from distinct disciplines and employ different theoretical frameworks. Even so, they share an interest in the role of the media and the communicative dynamics in the relation between individual and collective in situations of unrest and political change. As already implied, they are not given equal attention in this article, which is most firmly rooted in research on witnessing and outlines this body of literature systematically, while scholarship on connective action provides more specific insights into per- sonalized politics and the shift from collectivity to connectivity.

Connective witnessing manifests itself in various situations, when citizens and/or participants contribute to the flow of information from man-made and natural catastrophe by producing and distributing images on a large scale. Civic action has been chosen as the empirical example in this article because it constitutes a fairly new-coming and rapidly developing domain of connective witnessing. Moreover, witnessing in the context of protest thematizes the individualcollective relationship on two intertwined levels inasmuch as images taken by individual protesters depict the collective of people physically present and enter into new online collective/connective forms. Even though connective witnessing represents a conspicuous form of witnessing today, it obviously coexists with other forms of witnessing in journalism and the media at large (Frosh \& Pinchevski, 2009a; Peters, 2001; Zelizer, 2007).

This article is divided into five sections and starts out by introducing connective witnessing in relation to civic action. The second section critically revisits literature on witnessing in order to establish a historical platform for theorizing connective witnessing. Three interpretations of the relationship between the individual and the collective are identified (from the 1990s to the present) that are vital to understanding how connective witnessing transforms this relationship. The third section highlights the shift instigated by connective witnessing from the witness' tra- ditional claim to representativity to a personalized form of political participation. This is exem- plified through an analysis of images produced and disseminated by protesters on Ireport, CNN.com's platform for citizen reporting. In the fourth section, the 
connective distribution and consumption of witness testimonies is examined, again illustrated by footage from Ireport. Fifth and finally, the conclusion reflects on the historical changes and discusses the consequences of stretching the notion of witnessing.

\section{Connective witnessing and civic action}

Within the past few years, connective witnessing has established itself as a common way for par- ticipants and onlookers to communicate from ongoing protests and other initiatives of civic action. Connective witnessing serves the purpose of documenting the course of events, the turnout of people, the conduct of the authorities and fellow protesters, and so on. The footage functions as a way for participants to communicate and share experiences internally. But it also works as external communication to gain public visibility, recruit more followers, and raise financial, political, and moral support.

Connective witnessing has not least been rendered visible in the mainstream news media's frequently featured images of large crowds of people armed with mobile phones, ready to report events, ready to connect with each other and the outside world. These iconic represen- tations have surfaced in the coverage of a range of civic protests, for instance, in Iran (2009); Egypt, Syria, Libya, and other Middle Eastern/Northern African countries (from 2011); the London Riots (2011); Occupy Wall Street (2011); and demonstrations in Hong Kong (2014). Showing mass witnessing as well as witnessing of the mass, the images direct attention to the mobile phone as an expression of opposition and civil disobedience. By raising their mobile phones, protesters meta-communicate their status as alert, willing, and capable witnesses (see also Andén-Papadopoulos, 2014). The images emphasize how witnessing has become an integral part of civic action, which has a bearing on the orchestration, communication, media coverage, and political handling of events. Omnipresent mobile phones symbolize the common coupling of democratization movements and enhanced access to media technologies, especially in regimes formerly capable of suppressing information about initiatives critical of their exercise of power. However, mobile phones connote not only empowerment but also new possibilities of sur- veillance and counter-surveillance. Protesters are rendered more vulnerable by the options avail- able to monitor their movements and data traffic, for example, by spyware aimed at their mobile phones. In turn, demonstrators are able to document the conduct of authorities onsite, for instance, by live streaming.

The pictures of protesters holding up their mobile phones have turned into news icons (Bennett \& Lawrence, 1995; Mortensen, 2015) as recurrent, recognizable, and symbolically dense represen- tations of civic action. By showing ubiquitous smartphones, these images allude to the sheer mass of testimonies originating from subjective points of view and entering current 'cultures of connectivity' (Dijck, 2013). They underline the complexity of witnessing today, which this article attempts to conceptualize by developing the term 'connective witnessing'. Individual and collective acts of witnessing

To build the theoretical foundation for connective witnessing, several related and partially overlapping traditions could be drawn in. Most prominently, the literature on citizen journalism has engaged with the way in which digital technologies have made it possible for individuals outside the institutionalized media to contribute to the media circuit, but, of course, scholars taking this approach primarily see this development from the point of view of journalism studies 
(e.g. Allan \& Thorsen, 2009, 2014; Wall, 2012, 2015). Moreover, the literature on con- nective action, which this article also consults, on its own underpins the shift form collective to connectivity (e.g. Bennett \& Segerberg, 2012, 2013).

This literature's focus on political partici- pation, however, typically does not include the cultural and historical aspects, which are also significant to shed light on contemporary witnessing.

From the perspective of this article, there are three main advantages of conceptualizing the production, distribution, and mobilization of footage from crisis and conflict events by citizens within the framework of 'witnessing'. First of all, the rich literature offered by this scholarly tra- dition may provide historical and cultural perspectives, which are not only important to ground contemporary practices in a longer durée, but also to understand witnessing as a genre with certain aesthetic and narrative characteristics. In addition, the existing research on witnessing has diligently theorized the particular position of the witness, including the relation between the individual and the collective and the degree of participation inherent in every act of witnessing (see e.g. Felman \& Laub, 1992; Peters, 2001; Wagner-Pacifici, 2005). Finally, more recent litera- ture on witnessing has engaged with the same shift in witnessing from invited appearances in the media to the 'auto-mediated' witness (Mortensen, 2015) producing and distributing content him- or herself (Allan, 2013; Andén-Papadopoulos, 2014; Chouliaraki, 2010; Frosh \& Pinchevski, 2009a, 2009b; Mortensen, 2011a, 2011b; Pantti, 2013), albeit not provided a conceptual frame- work similar to 'connective witnessing'.

Why has witnessing continued to interest and intrigue scholars across different disciplines such as comparative literature, memory studies, media studies, and sociology? Much of this atten- tion probably stems from the cultural and political significance attributed to witnesses, because they play a 'crucial hinge role in moments of social and political transformation', as Wagner-Paci- fici contends (2005, p. 201). During war, conflict, natural catastrophe, and other situations of unrest, witness testimonies gain centrality by offering details or giving perspectives on matters unknown, uncertain, or disputed. For this reason, witnesses contribute to laying new, fragile ground through their testimonies (see also Mortensen, 2015). They are called upon to bear witness to 'a vision of the world that is re-made at the very moment when witnessing becomes relevant' (Wagner-Pacifici, 2005, p. 206, italics in original text). Accordingly, the stakes are often high in testimonies and they enduringly raise the question of representativity: On whose behalf do witnesses speak? Witnessing has traditionally been interpreted as the retrospective spoken or written account of events, which does not merely fulfil personal needs for self- expression or individual recognition but addresses experiences shared by others and/or sheds light on matters of relevance to the general public. In this way, the conventional role performed by witnesses in the media bears a strong resemblance to that of the legal witness, who is also sum- moned to testify in matters of dispute or uncertainty for the sake of justice and the common good (and, of course, a number of witnesses appear both in the legal system and in the media system). Another parallel between media and juridical practices is that the subjective viewpoint of the legal witness continues to raise doubt about this figure's ability and willingness to convert experience into testimony in a fair, direct, and transparent manner. Similarly, the media have counterbalanced the eyewitness' subjective disposition and usually incoherent narrative by offering a ritualized role (Thomas, 2009, p. 101), which structures and frames acts of witnessing in order to transform singular observations and sensations into generalizable ones. 
Interpretations of witness testimonies often underscore how they oscillate between document- ing specific episodes and general circumstances, and between showing private recollections and insights of relevance to the larger public. The Abu Ghraib pictures constitute a famous case in point. Initially, the snapshots were circulated privately among the prison guards, but later they were the subject of intense interest from an international public and became important evidence in subsequent legal proceedings. Debates ensued about whether they reflected the standpoint of the military employees in question or whether they epitomized the general values of the US mili- tary. A related and equally heated discussion concerned whether the pictures represented isolated instances or exemplified the typical conduct of US soldiers.

Research on the witness since the 1990s offers three overall interpretations of this tension between the individual and the collective: (1) the individual speaking on behalf of the collective (e.g. Felman \& Laub, 1992); (2) the collective witnessing of events mediated in the mass media (e.g. Ellis, 2000); and (3) eyewitness images entering the news circuit as 'mass self-communi- cation' (Allan, 2007; Andén-Papadopoulos, 2014) or 'embodied collectivity' (Pantti, 2013). Of course, it might seem schematic and reductive to summarize the intellectually rich literature on the witness and witnessing across three generic periods and focus attention on the relationship between the individual and the collective. This priority is motivated by the need to provide a theoretical and historical platform for interpreting connective witnessing as a reconfiguration of this relationship.

\section{The individual speaking for the collective: witnessing as instant and instance}

In the 1990s, researchers such as Felman and Laub (1992) and Caruth (1995), representing pri- marily literary and psychoanalytic studies, took an interest in witnessing (later contributions include Ekman \& Tygstrup, 2008; Frosh \& Pinchevski, 2009a; Peters, 2001, 2005). Felman and Laub co-authored the most important work within this school, Testimony: Crises of witnessing in literature, psychoanalysis, and history (1992), which centres on the cultural prominence of testimonies from Holocaust survivors. As the subtitle of the book suggests, testimonies emerge from a state of crisis in the individual traumatized by having been present at a major his- torical crisis. 'It is impossible for the witness to remain silent; but it is also impossible for the witness to describe the event', as Peters argues (2001, p. 713). Felman and Laub regard witnes- sing as the privilege and obligation of survivors to claim responsibility not only for their own story but also for the general writing of history. This resonates with the conventional interpretation of witnessing as the lot of individuals believed to be on the right side of history and trusted to have the moral prerogative to tell the factual and truthful version of events.

Yet, the relationship between the individual and the collective is anything but straightfor- ward. The witness carries 'a radically unique, noninterchangable and solitary burden' (Felman, 1992, p. 3), insofar as the exclusive and singular testimony cannot be articulated or repeated by any other. Romanian-born poet Paul Celan (1920-1970) expresses the lot of the witness in the last stanzas of his famous poem Ashglory (Aschenglorie): 'No one/ bears witness for/ the witness' (Niemand/zeugt für den/Zeugen) (Celan, 1968, p. 68). Even if indi- vidual testimonies are regarded as irreplaceable, witnessing mainly becomes significant when utterances are recognized as paradigmatic. Jacques Derrida observes along these lines that acts of witnessing come with the assertion that the singular is 'universalizable'. They involve an instant (singular instance) as well as an instance (ideal instance) (Derrida, 2000, pp. 41-42). The event is first dealt with as a 
privately experienced instant. Yet, when the indi- vidual transmits the experience as if it were or ought to be a matter of public significance, it is offered as an instance, that is, 'repeatable and designed for reiteration' (Frosh \& Pinchevski, 2009b, p. 7).

The privileging of the Holocaust survivor as the witness per se has called for criticism (e.g. Mortensen, 2015; Thomas, 2009) and is obviously contested by the more inclusive understanding of this figure underlying 'connective witnessing'. Be that as it may, the diligent theorization of the transition from private experience to public utterance remains illuminating for the particular pos- ition of the witness. According to Peters, 'the journey from experience (the seen) into words (the said) is precarious' (2001, pp. 709-710). Digital technologies have collapsed the distance from the seen to the said by transforming witnessing into a participatory and self-reflexive act that instantly turns experiences into representations. The transition from seeing to saying nonetheless continues to be intricate or indeed 'precarious', to use Peters' own term. However, focus has shifted from the existential struggle of the witness to the assessment of the authenticity, meaning, and significance of eyewitness images, for instance, when they are used in the news media or by human rights organizations.

\section{Collective media witnessing: responsible without agency?}

The second scholarly reception emerged from media studies around the turn of the century and broadened the scope of witnessing. Audiences were conceptualized as a collective of witnesses to mediated experiences remote in space, but not necessarily in time (e.g. live reportage from areas of disaster). In his influential work, Seeing things: Television in the age of uncertainty (2000), John Ellis proposes that the twentieth century was sealed as the century of witness by tele- vision facilitating a new generalized mode of witnessing. Ellis encapsulates this domestic form of witnessing in the sentence '[w]e cannot say that we do not know'. These often-quoted words imply that parallel to first-hand witnessing, media witnessing entails a certain responsibility. However, this seems to be accompanied by little or no individual agency. As Ellis argues, audi- ences obtain a 'powerless knowledge and complicity' from the safety of their homes (2000, p. 1, but see Ellis, 2009a, 2009b for revision of this position).

Theoretically and empirically, it is difficult to contain in the same concept the essential differ- ences between the firsthand witness' presence in the physical world and the second-hand witness' presence in front of the screen. Partially in response to Ellis (2000), Peters stresses that by contrast to media witnessing, first-hand witnessing carries 'weighty baggage', involving sacrifice and suffering on account of the heritage from Holocaust and other atrocious events (Peters, 2001, p. 708). Even so, the collective experience involved in media witnessing constitutes an important precondition for conceptualizing connective witnessing as the collective of media users turned into media producers. Theory on media witnessing also contributes significantly to the understanding of the witness by releasing this concept from the ties to particular historical circumstances and a fixed notion of the witness as an individual on the right side of history deli- vering spoken or written statements.

\section{Eyewitness images: mass self-communication or embodied collectivity}


Paul Frosh and Amit Pinchevski argue that 9/11 'is the event that cannot not produce witnesses' (2009b, p. 8, italics in original text). This double negative applies to an increasing extent to situations of unrest to which onlookers, participants, victims, and others respond by producing, distributing, and mobilizing images. Grounded in theory on witnessing, research on this subject has examined how eyewitness images have infused the mainstream news media, especially in relation to breaking news events. Attention has been redirected to the individual first- hand witness but with the crucial difference that witnesses themselves create and disseminate tes- timonies (Allan, 2013, 2014a, 2014b; Andén-Papadopoulos, 2014; Chouliaraki, 2010; Morten- sen, 2011a, 2011b, 2014, 2015; Pantti, 2013; Reading, 2009). The focus of this research coincides with the historical period and to some extent also the thematic issues covered by this article. However, as these studies typically centre on selected images rendering the crisis (more) visible in the news coverage, they tend to refrain from explicitly addressing the relation between the individual and the collective. There are two notable exceptions of particular interest to connective witnessing, which are laid out in the following.

First, the individual-collective relationship is approached in Allan's (2007) and Andén-Papadopoulos' (2014) deployment of Manuel Castells' term 'mass self-communication' in their analyses of eyewitness images. This concept is applicable to connective witnessing insofar as the rise of mass self-communication enhances 'opportunities for social change' (Castells, 2009, p. 8) and is distinguished by 'autonomy, horizontal networking, interactivity, and the recombination of content under the initiative of the individual and his/her networks' (Castells, 2009, p. 125). However, this article refrains from using the concept 'mass self-communication' because the con- nectivity of communicative flows needs to be foregrounded, and 'mass' may be confusing in this context by referring to both the 'mass' of communicative acts and the assembled 'mass' of people.

Second, with the notion of 'embodied collectively', Pantti (2013) departs from the obser- vation that often the bodily presence of citizen photographers is discernible as an extra textual layer in the footage in the form of breathing, shouting or pointing fingers. She ascribes 'embodied collectivity' to producer, audience, and text, thus including the components of the classical com- munication model:

The embodied practice of the photographer does not mean that only the individual photographer is important. On the contrary, the photographer in citizen images emerges as an embodied collectivity, as a figure inviting herself to be imagined as 'anyone'. This structure of 'from-anyone-to-anyone' (cf. Scannell, 2000) constructs a collectivity between the depicted others and 'us'. Citizen images as a col- lective affective space are also sustained at the visual level by the prominent trope of the raised camera, which signifies the importance of the event and the authenticity of the participants' perspec- tive on it (Becker, 2012). At the textual level, this sense of collectivity is reinforced by the captions, which make images, on the one hand, 'authorless' by attributing images to recording devices ('cap- tured by a camera phone'), content-sharing sites (e.g. 'loaded from YouTube video service') and distribution channels (e.g. 'distributed by news agency') and, on the other hand, attributing them to a collective figure (citizen, activist). (Pantti, 2013, p. 210)

Pantti points out that the producer lends herself to being imagined as 'anyone', and that this 'anyone' constructs a collectivity between audience and text. She further explains that on the textual level, collectivity manifests itself in terms of both 'collective affective space' and the attri- bution of authorship to 'collective figures'. Pantti's conceptualization of collectivity in terms of intertwined physical and virtual publics is most illuminating for the 
arguments pursued in this article regarding connectivity as a reconfiguration of the claim to collectivity in acts of witnessing. However, this still raises the question of whether producers, audiences, and texts can be this seam- lessly united in the production, circulation, and consumption of the images. From the perspective of this article, this line of argument fails to take into account that civic action tends to favour personalized expressive forms and individual communicative networks at the expense of collective identities.

To sum up, the three generations of literature on witnessing feed into the concept of connec- tive witnessing by offering different interpretations of the relationship between the individual and the collective. The interpretations are based on the prevailing media for witnessing and events witnessed during these periods and range from survivors speaking on behalf of the collective to media witnessing by the audience to eyewitness images as either mass self-communication or col- lective embodiment. Connective witnessing returns to the individual first-hand eyewitness, shifts the broad notion of the witness inherent in 'media witnessing' from the audience to the audience- as-producers, and follows in the footsteps of Allan (2007), Andén-Papadopoulos (2014), and Pantti (2013) by moving beyond understanding eyewitness images in relation to their circulation in the news media and conceptualizing witnessing as a participatory act. Taking this as a point of departure, the following sections present connective witnessing and exemplify this concept with Ireport, CNN's hub for citizen footage, first in terms of personalized political participation and then connectivity.

\section{Personalized political participation}

The position of the individual taking part in connective witnessing might be regarded as a mani- festation of what Kevin McDonald designates 'personalized politics'. He explains that

... we need to break with a paradigm of 'collective identity' and begin to explore social movements and conflicts in terms of a 'public experience of self'. This points to an emerging pattern of social movement where it is not 'collective identity' that is mobilized, but where action instead needs to be understood in terms of a shared struggle for personal experience. (McDonald, 2002, pp. 124-125)

McDonald's interpretation of personalized politics as, on the one hand, 'public experience of the self' and, on the other, 'shared struggle for personal experience' constitutes a relevant framework for understanding connective witnessing, which follows the general tendency for political partici- pation to move from the conventional realms of political parties, NGOs, and so on to horizontal, individualized networks. As Loader, Vromen, and Xenos highlight in connection with 'network- ing young citizens', participants are more 'project oriented' and engaged reflexively 'in lifestyle politics', which is 'not dutiful but self-actualizing' (2014, p. 145).

Connective witnessing merges political participation and self-expression. As such, it represents an example of 'first person media' (Dovey, 2000, p. 1), contributing to the omnipresence of personal confessions and the subjective viewpoints of 'ordinary' people in today's media and culture. This might be unfolded empirically by analysis of footage from Ireport, CNN.com's platform for citizen reporting. Launched in 2006, Ireport receives on average 500 reports a day from people submitting footage in response to one of their 'assignments', which typically cover topical events, subjects, and debates (http://ireport.cnn.com/community/assignment2015). Stories uploaded to iReport 'are not edited fact-checked or screened before they post. Only stories marked "CNN iReport" have been verified and cleared by 
CNN', as iReport stresses in the section 'Frequently asked questions' (http://ireport.cnn.com/faq.jspa). This section also draws institutional demarcation lines between $\mathrm{CNN}$ and citizen journalists by stating that '[b]eing an iReport user and creating and uploading content to $\mathrm{CNN}$ iReport does not mean that you work for CNN, and you should never represent yourself as working for CNN'. Even when $\mathrm{CNN}$ uses footage by citizens in its regular news cover- age, contributing to Ireport always constitutes unpaid labour, as a study by Palmer (2013) has made clear. Ireport might serve as an example of connective witnessing, because citizens/participants enduringly upload their footage to this platform of ongoing events, including protests and other kinds of civic action, thus forming a fragmented and diffuse connective patchwork of first-hand tes- timonies from the events in question.

The name of this site, Ireport, is indicative of the narration and style of the posted reports, which are clearly seen from the perspective of the individual ' $I$ ' behind the camera (the name of course also includes a pun on the phonetic likeness between 'eye' and 'I'). For instance, the

assignment 'Protests around the World', established 11 July 2014, and hosting 466 stills and videos as of 14 December 2014, shows protests from a fragmented and de-contextualized point of view. In the words of Tamar Ashuri and Amit Pinchevski, this footage demonstrates how the proximity of the first-hand witness causes an 'annihilation of perspective' (2009, p. 140). Connective witnessing reproduces the immediate and subjective experience of being then and there as events play out. The images do not present a synthesized and informational nar- rative, but rather slices of ongoing action as suggested in these randomly picked examples:

One photograh, posted on 8 December 2014, shows uniformed policemen lined up at a crossroads in an urban setting.1 The title 'Protesting in Berkeley, Ca IMG_0510.JPG' indicates the place but seems otherwise to be automatically generated by a mobile phone. This is also the case with the only other bit of information, the standard message: 'Sent from my iPhone'. CNN.com categorizes the sender as 'unclaimed'.

Another photograph, posted 6 December 2014, by the alias RooseveltB00, shows anti-gov- ernment protesters in Portau-Prince, Haiti, holding up pictures of Russian president Vladimir Putin.2

A seven-second video from 7 December 2014, simply titled IMG_0514.MOV.mov, also by an 'unclaimed' producer, shows a crowd of demonstrators yelling 'don't shoot, hands up', probably in protest of police violence in the United States. 3

A final example of the diversity of footage posted in 'Protests around the world' is a photo- graph uploaded by 'Rofik' on 5 December 2014, depicting protesters in Malang, Indonesia, wearing masks, holding up money, and carrying a sign with the inscription 'Rejection of subsi- dized fuel hike.' 4 As most of the material posted in this assignment, CNN.com disclaims these posts as 'Not verified by CNN.'

These four examples are characteristic of the paradox presented by the production and disse- mination of eyewitness images from protests, which the concept of connective witnessing attempts to capture. Even though the footage shows crowds of people gathered to fight for the same cause, it depicts events from a highly subjective and partial perspective. 
This is not least emphasized by the fact that the pictures are often out-of-focus and shaky, thus self-reflexively pointing back to the bodily presence of the individual taking them and confirming his or her attendance as, precisely, a witness. By contrast, the people depicted seem to be caught unaware of the camera, and seldom engage in dialogue or other visible and audible forms of inter-action with the person recording. The physical proximity conveys the impression that the produ- cer of the footage is part of the crowd, yet the ostensible lack of contact suggests distance, thus rendering solidarity and collective identities ambivalent.

One may question what kind of participation is entailed in the personalized political partici- pation exemplified by Ireport. From the literature on the traditional witness, we may gather that witnessing per definition entails participation or, as a minimum, involvement, as every act of wit- nessing is tied to a 'transformation' (Thomas, 2009, p. 96; see also Peters, 2001, 2005; Mortensen, 2015; Wagner-Pacifici, 2005). However, connective witnessing involves more active, urgent, direct, and self-reflexive participation. Witnessing becomes part of the event, changing the witness' perception of the event, the retrospective reconstruction of the event, and sometimes even the course of the event itself. The mere physical presence of the camera is often enough to exert an influence, most dramatically in regimes interpreting filming in public spaces as a sign of dissent, but also on a smaller scale when people become conscious of a camera pointing in their direction. Events take place in front of the lens, which would not otherwise have happened in that way, or would perhaps not have happened at all. A strong indication that witnessing has turned into political involvement and resistance is the fact that human rights organizations such as Witness train activists in the use of video to secure records of their political struggle and monitor the conduct of the authorities. As implied by the motto of this organization, 'See it, film it, change it', witnessing is once again linked to political change and the space in between media and law (http://witness.org, see also the article by Sam Gregory (in press)).

The abundance of tunnel-visioned and fragmented clips created and circulated as personalized political participation raises afresh the issue of the witness' representativity at the heart of the concern about the relation between the individual and the collective. When the images are not contextualized by, for instance, media institutions or human rights organizations, the gap between the individual and the collective appears not to be readily closed. Witnessing still involves the basic struggle to gain visibility and recognition, but seems to have undergone a change from the pursuit of representativity to a form of participation, from taking on collective claims in the mass media to personalized politics through connective media.

\section{Connectivity taking the place of collectivity}

Connective witnessing in relation to civic action, it is argued in this article, has emerged out of personalized politics and the blurring boundaries between the collectivity of physical protests and the connectivity of online protests. The question remains of how these personalized and par- ticipatory statements enter into a shared connective space, constituting a less obligated and less systematic form of collectivity. In this context, connectivity might be outlined in accordance with the work by Bennett and Segerberg (2012, 2013, see also 2011) on the emergence of con- nective action, which converges with or replaces collective forms of action in protest movements: 
The logic of connective action is rooted in self-motivated sharing and what Benkler (2006) termed 'peer production'. Such connective networks grow to the extent that people can engage in content themes that are amenable to personalization, appropriation, and collaboration through the sharing of ideas and multimedia content, as well as through access to technologies that enable such sharing. (Bennett \& Segerberg, 2013, p. 196)

Similar to Bennett and Segerberg, this article views connective witnessing as the sharing of visual, non-professional footage from protest events in a manner inviting ‘personalization, appropriation, and collaboration' (2013, p. 196). Taking another look at Ireport on CNN.com might illustrate this point.

Regarded as whole, the material posted in Ireport's assignment 'Protests around the World' forms a sense of 'connected presence' (Licoppe \& Smoreda, 2005). The footage is presented hori- zontally and can be organized and customized according to the preferences of viewers. Categories such as 'most recent', 'most viewed', and 'on CNN' can be chosen to reorder the images in diverse and, quite literally, thousands patterns of meaning. Users are clearly positioned as 'inter- active producers and consumers of knowledge' (Dijck, 2007, p. 116). However, an implicit hier- archy exists inasmuch as a few of the images are featured in CNN's news coverage and thus cross the line between non-professional and professional practices of journalism. But this hierarchy is only revealed if one re-orders the images according to the category 'on CNN', or take note of the absence of the usual disclaimer 'Not verified by CNN' on the small amount of images used by this news channel in its regular online or broadcast coverage.

Ireport functions as a dynamic and open-ended archival structure in keeping with the general turn to 'a new media culture built on permanent transfer' (Ernst, 2002, p. 23, cited after Røssaak, 2010, p. 11). The meaning of individual testimonies and the collection of testimonies are contin- gent on the architecture and affordances of the platform as well as the users' navigation of the site, that is, their special areas of interest or more casual modes of consuming the images. They are, in the words of José van Dijck, 'tweaked in response to their users' needs and their owners' objec- tives, but also in reaction to competing platforms and the larger technological and economic infrastructure through which they develop' (2013, p. 7). This creates new opportunities for frame- works and comparisons made possible not least by the fact that the clips in most cases appear detached from their original geographical, political, social, and cultural contexts by the lack of information and framing. To sum up, the meaning making offered by connective witnessing might be interpreted in opposite terms: On the one hand, it emerges as specific and narrow due to the subjective, particular viewpoint. On the other hand, the potential meaning to be deduced is abstract and general inasmuch as the footage readily lends itself to being recontextualized.

Considered from an ethical or normative perspective, the 'opening up of the space of appear- ance to the witnessing of citizens', as Chouliaraki expresses it, has called for concern that it is 'becoming not only richer but also riskier, not only more "democratic" but also more "demotic" (2010, p. 307). Connectivity as an alternative collectivity does not come with the same moral authority as the classical eyewitness, covering the distance between individual and collective. Rather, connective witnessing leaves more of the contextualization and assessment up to users and/or news agencies and institutions, human rights organizations, and others deploy- ing eyewitness images. For instance, the very crowd of people responsible for the arrest and killing of Muammar Gaddafi in 2011 also documented the sequence of events from various angles and shared this footage online almost live. This material became the central element of the initial news 
coverage, but also left the mainstream media fumbling with how to evaluate these images originating from the parallel procedures of lynching the former dictator and documenting the course of the event (Kristensen \& Mortensen, 2013, 2014). When bearing witness seizes to be the privilege or duty of particular people under special circumstances, and when every onlooker and every participant may join the ranks of eyewitnesses, the moral imperative is negotiable.

While connectivity does not present the classical authoritative narrative of the eyewitness speak- ing for the collective, the many disparate testimonies still possess the potential for making a group statement. On 'Protests around the World' and other reservoirs for footage from protests on Ireport and elsewhere, the sheer number of assembled clips is a clear message of the volumes of protest initiatives and people taking active part in them. Moreover, a sense of unity and cross-inspiration is suggested by the similar forms of expression across the many dissimilar causes and contexts. All in all, connective witnessing may be interpreted either as scattered documentation of specific inci- dents or as a general mode of communicating protest, since this heterogeneous material is tied together by protest as the overall subject matter and the uniformity of the narration and aesthetics.

\section{Conclusion: connective witnessing}

Introducing the concept 'connective witnessing', this article has made the argument that to an increasing extent, witnessing may be understood as a participatory, reflective act by individuals, who, by creating and circulating media content, contribute to current cultures of connectivity. This understanding marks a definitive change from the way witnessing has traditionally been conceptualized as invited (mass) media appearances, which transformed experiences into ritualized nar ratives and performances. By placing emphasis on the participatory aspect, connective witnessing not only captures ongoing changes to acts of witnessing and political participation but also accentuates the increasing overlap between the two. Depending on focus, one may speak of witnessing as a personalized form of political participation or personalized political participation in the form of witnessing. An important historical point to be picked up from previous work on witnessing is that this act has always involved a participatory element.

The critical review of the literature on the witness and witnessing established a platform for characterizing connective witnessing by comparing it to earlier forms of witnessing and the theoretical conceptualization thereof. Two major changes take place from the initial theoretization of the witness by Felman and Laub (1992) and others. First, as stipulated by theory on media

witnessing by Ellis (2000) and others, the figure of the witness is not delimited to victims of atrocious events but understood in wider strokes. Witnessing thus attains a less exclusive status, and some of the moral and existential weight historically associated with this act is reduced. Second, as reflected upon in the literature on the circulation of eyewitness images in the news by among others Andén-Papadopoulos and Pantti (2011), Allan (2013), and Mortensen (2014, 2015), a shift has taken place from the witness performing in the media to witnesses producing and distributing their own pictures. Connective witnessing encompasses both of these changes. But the term is also an attempt to take 
the conceptualization a step further by considering the reconfiguration of the relationship between individual and collective in personalized political participation and connective action.

Traditionally, the individual speaking for the collective secured the witness an important position in the writing of history. Due to the horizontal and decentred ordering of connective witnessing, singular testimonies only become important in rare cases, such as the footage of the shooting of Neda Agha Soltan during a demonstration in Iran in 2009 , who became an icon for the political struggle in the international news media (Mortensen, 2011a). Mass witnessing opens up for a mul- titude of singular, subjective perspectives and various patterns of meaning, which, when combined, make a statement about the engagement and inspiration across different contexts and the new ways in which citizens are able to document ongoing action. In this manner, connective witnessing once more ties witnessing to social and political change and to the potential for crossing the line to the legal sphere.

A critical question in this regard concerns whether the notion of the witness is stretched to the extent that the concept loses its critical nerve and precision of meaning. On this issue, I agree with Stuart Allan, who argued at the seminar Streets to screens: Mediating conflict through digital networks at Goldsmiths University on 7 November 2014 that the term should be preserved because it ties the scholarly conceptualization of witnessing to the everyday use of this notion and, in particular, to the way in which it is deployed in the contexts of news production and protest movements (see also the article by Stuart Allan and Chris Peters (in press)). Witnessing has over the past years gained a broader significance, and by referring to current practices of picture making and sharing as acts of witnessing, two important purposes are served: We are able to view the current proliferation of witnessing in a longer historical and cultural perspective and contextualize it within the resourceful theory already developed on this issue. Moreover, we are able to anchor research more firmly within discourses and practices of communication relating to connective action, crisis communication, conflict reporting, and so on, which are commonly understood and referred to in terms of witnessing.

\section{Disclosure statement}

No potential conflict of interest was reported by the author. Notes

1. http://ireport.cnn.com/docs/DOC-1195263 (last accessed 9 February 2015).

2. http://ireport.cnn.com/docs/DOC-1195122 (last accessed 9 February 2015).

3. http://ireport.cnn.com/docs/DOC-1195265 (last accessed 9 February 2015).

4. http://ireport.cnn.com/docs/DOC-1194601 (last accessed 9 February 2015)

Note on contributor

Mette Mortensen University of Copenhagen, Media, Cognition and Communication, Karen Blixens vej 4, Copenhagen S, DK-2300

Denmark. [email: metmort@hum.ku.dk]

\section{References}


Allan, S. (2007). Citizen journalism and the rise of 'mass self-communication': Reporting the London Bombings. Global Media Journal. Australian Edition, 1(1), 1-20.

Allan, S. (2013). Citizen witnessing: Revisioning journalism in times of crisis. Cambridge: Polity Press. Allan, S. (2014a). Witnessing in crisis: Photo-reportage of terror attacks in Boston and London. Media, War \& Conflict, 7(2), $133-151$.

Allan, S. (2014b). Reformulating photojournalism: Interweaving professional and citizen photo-reportage of the Boston bombings. In S. Allan \& E. Thorsen (Eds.), Citizen journalism. Global perspectives (Vol. 2, pp. 155-169). New York, NY: Peter Lang.

Allan, S., \& Peters, C. (in press). Visual truths of citizen reportage: Four research problematics. Information, Communication \& Society. doi:10.1080/1369118X.2015.1061576

Allan, S., \& Thorsen, E. (2009). Citizen journalism: Global perspectives (Vol. 1). New York, NY: Peter Lang.

Allan, S., \& Thorsen, E. (2014). Citizen journalism: Global perspectives (Vol. 2). New York, NY: Peter Lang.

Andén-Papadopoulos, K. (2014). Citizen camera-witnessing: Embodied political dissent in the age of 'mediated mass selfcommunication'. New Media \& Society, 16(5), 753-769. doi:10.1177/1461444813489863

Andén-Papadopoulos, K., \& Pantti, M. (2011). Amateur images and global news. Bristol: Intellect. Ashuri, T., \& Pinchevski, A. (2009). Witnessing as a field. In P. F. a. A. Pinchevski (Ed.), Media witnessing. Testimony in the age of mass communication (pp. 133-157). Basingstoke: Palgrave Macmillan.

Bennett, W. L., \& Lawrence, R. G. (1995). News icons and the mainstreaming of social change. Journal of Communication, 45(3), 20-39.

Bennett, W. L., \& Segerberg, A. (2011). Digital media and the personalization of collective action. Information, Communication \& Society, 14(6), 770-799.

Bennett, W. L., \& Segerberg, A. (2012). The logic of connective action. Information, Communication \& Society, 15(5), 739-768.

Bennett, W. L., \& Segerberg, A. (2013). The logic of connective action: Digital media and the personalization of contentious politics. Cambridge: Cambridge University Press. 
Caruth, C. (Ed.). (1995). Trauma: Explorations in memory. Baltimore, MD: Johns Hopkins University Press. Castells, M. (2009). Communication power. Oxford: Oxford University Press.

Celan, P. (1968). Atemwende. Frankfurt am Main: Suhrkamp.

Chouliaraki, L. (2010). Ordinary witnessing in post-television news: Towards a new moral imagination. Critical Discourse Studies, 7(4), 305-319.

Derrida, J. (2000). The instant of my death. Stanford, CA: Stanford University Press.

Dijck, J. van. (2007). Mediated memories in the digital age. Stanford, CA: Stanford University Press. Dijck, J. van. (2013). The culture of connectivity: A critical history of social media. Oxford: Oxford University Press.

Dovey, J. (2000). Freakshow: First person media and factual television. London: Pluto Press.

Ekman, U., \& Tygstrup, F. (2008). Witness: Memory, representation and the media in question. Copenhagen: Museum Tusculanum Press.

Ellis, J. (2000). Seeing things: Television in the age of uncertainty. London: I.B. Tauris.

Ellis, J. (2009a). Mundane witness. In P. Frosh \& A. Pinchevski (Eds.), Media witnessing. Testimony in the age of mass communication (pp. 73-88). Basingstoke: Palgrave Macmillan.

Ellis, J. (2009b). What are we expected to feel? Witness, textuality and the audiovisual. Screen, 50(1), 67-76. doi:10.1093/screen/hjn077

Gregory, S. (in press). Ubiquitous witnesses: Who creates the evidence and the live(d) experience of human rights violations? Information, Communication \& Society.

Felman, S. (1992). Education and crisis, or the vicissitudes of teaching. In S. Felman \& D. Laub (Eds.), Testimony: Crises of witnessing in literature, psychoanalysis, and history (pp. 1-56). New York, NY: Routledge.

Felman, S., \& Laub, D. (1992). Testimony: Crises of witnessing in literature, psychoanalysis, and history. New York, NY: Routledge.

Frosh, P., \& Pinchevski, A. (Eds.). (2009a). Media witnessing. Testimony in the age of mass communication. Basingstoke: Palgrave Macmillan. 
Frosh, P., \& Pinchevski, A. (2009b). Introduction: Why media witnessing? Why now? In P. Frosh \& A. Pinchevski (Eds.), Media witnessing: Testimony in the age of mass communication (pp. 1-19). Basingstoke: Palgrave Macmillan.

Hoskins, A. (2011). 7/7 and connective memory: Interactional trajectories of remembering in post-scarcity culture. Memory Studies, 4(3), 269-280.

Kristensen, N. N., \& Mortensen, M. (2013). Amateur sources breaking the news, metasources authorizing the news of Gaddafi's death. New patterns of journalistic information gathering and dissemination in the digital age. Digital Journalism, 1(3), 352-367.

Kristensen, N.N., \& Mortensen, M. (2014). Non-professional visuals framing the news coverage of the death of Muammar Gaddafi. In D. R. Christensen \& S. Sandvik (Eds.), Mediating and remediating death (pp. 133-154). Farnham: Ashgate.

Licoppe, C., \& Smoreda, Z. (2005). Are social networks technologically embedded? How networks are changing in communication technology. Social Networks, 27, 317-335.

Loader, B. D., Vromen, A., \& Xenos, M. A. (2014). The networked young citizen: Social media, political participation and civic engagement. Information, Communication \& Society, 17(2), 143-150.

Mcdonald, K. (2002). From solidarity to fluidarity: Social movement beyond collective identity - the case of globalization conflicts. Social Movement Studies, 1(2), 109-128.

Mortensen, M. (2011a). When citizen photojournalism sets the news agenda: Neda Agha Soltan as a web 2.0 Icon of post-election Unrest in Iran. Global Media and Communication, 7(1), 4-16.

Mortensen, M. (2011b). The eyewitness in the age of digital transformation. In K. Andén-Papadopoulos \& M. Pantti (Eds.), Amateur images and global news (pp. 61-76). Bristol: Intellect Press.

Mortensen, M. (2014). Eyewitness images as a genre of crisis reporting. In S. Allan \& E. Thorsen (Eds.), Citizen journalism: Global perspectives (Vol. 2, pp. 143-154). New York: Peter Lang.

Mortensen, M. (2015). Eyewitness images. Digital media, participation, and conflict. New York: Routledge. Palmer, L. (2013). 'iReporting' an uprising: CNN and citizen journalism in network culture. Television and New Media, 14(5), 367-385.

Pantti, M. (2013). Getting closer? Encounters of the national media with global images. Journalism Studies, 14(2), 201-218.

Peters, J. D. (2001). Witnessing. Media, Culture \& Society, 23(6), 707-723.

Peters, J. D. (2005). Courting the abyss: Free speech and the liberal tradition. Chicago, IL: University of Chicago Press. Reading, A. (2009). Mobile witnessing: Ethics and the camera phone in the 'war on terror'. Globalizations, 6(1), 61-76.

Røssaak, E. (2010). The archive in motion. Oslo: National Library. 
Thomas, G. (2009). Witness as a cultural form of communication. In P. Frosh \& A. Pinchevski (Eds.), Media witnessing. Testimony in the age of mass communication (pp. 89-111). Basingstoke: Palgrave Macmillan.

Wagner-Pacifici, R. (2005). Witness to surrender. In B. S. a. L. T. B. John R. Hall (Ed.), Visual worlds

(pp. 201-222). London: Routledge.

Wall, M. (2012). Citizen journalism: Valuable, useless, or dangerous? New York, NY: International Debate Education Association.

Wall, M. (2015). Citizen journalism. Digital Journalism, 1-17. doi:10.1080/21670811.2014.1002513 Zelizer, B. (2007). On 'having been there': 'Eyewitnessing' as a journalistic key word. Critical Studies in Media Communication, 24(5), 408-428. 